\title{
Tunable white-light emission hybrids based on lanthanide complex functionalized poly (ionic liquid): Assembly and chemical sensing
}

\author{
Haoxing Dang ${ }^{\mathrm{a}}$, Ying Li ${ }^{\mathrm{a}, \mathrm{b}, *}$, Hua Zou ${ }^{\mathrm{a}}$, Shenghua Liu ${ }^{\mathrm{a}}$ \\ ${ }^{a}$ School of Material Science \& Engineering, University of Shanghai for Science and Technology, Shanghai, 200093, PR China ${ }^{\text {b }}$ \\ State Key Laboratory of Molecular Engineering of Polymers (Fudan University), Shanghai, 200093, PR China
}

\section{A R T ICLEINFO ABSTRACT}

\section{Keywords:}

Lanthanide complexes Poly

(ionic liquid)

Tunable luminescence

Fluorescence sensing

\begin{abstract}
A series of novel poly (ionic liquid) based lanthanide hybrid materials POSS-PVIM@ $\left[\mathrm{Ln}(\mathrm{DBM})_{3}\right](\mathrm{Ln}=\mathrm{Eu}, \mathrm{Tb}, \mathrm{Gd}, \mathrm{DBM}=$ Dibenzoyl methane, PVIM = Polyvinyl imidazole, POSS =polyhedral oligomeric silsesquioxane.) have been synthesized by the copolymerization of POSS with lanthanide functionalized ionic liquid [Ln $\left.(\mathrm{DBM})_{3}\right]$ @ VIM-PA. The obtained hybrids were characterized by FT-IR, X-ray diffraction, XPS, TGA and luminescence spectroscopy. POSS-PVIM@ [Eu (DBM) 3 ] and POSSPVIM@[Tb $\left.(\mathrm{DBM})_{3}\right]$ exhibit the characteristic emission of center ions, which indicate that POSS-PVIM could effectively sensitize $\mathrm{Eu}^{3+}$ and $\mathrm{Tb}^{3+}$. More Especially, the luminescent color can be tuned into white excited at $300 \mathrm{~nm} \mathrm{UV}$ when the ratio of three different lanthanide cations $\left(\mathrm{Eu}^{3+}, \mathrm{Tb}^{3+}, \mathrm{Gd}^{3+}\right)$ is 1:3:3. Furthermore, the luminescence films are also prepared, which shows the uniformity and transparency. Light and thermal stability of these as-obtained samples are also improved due to the long chain structure of polymer and rigid skeleton of POSS. In addition, the fluorescent sensing property of the POSSPVIM@[Eu $\left.(\mathrm{DBM})_{3}\right]$ was investigated in detail, which shows selective luminescence quenching effect for $\mathrm{Cr}_{2} \mathrm{O}_{7}^{2--}$. These results provide meaningful data for the multi-component assembly and responsive luminescent of photo functional hybrids based on Poly (ionic liquid) and lanthanide, which can be expected to have potential application in the luminescent sensor devices.
\end{abstract}

\section{Introduction}

Ionic liquids (ILs) referring to the organic salts, are composed of large organic cations combined with various anions. Ionic salts in molten form, which are named "solvents of the future" or "designing solvents," are of particular importance because of the accessibility of mobile ions in a solvent-free medium, very low vapor pressures, good electric conductivity, large electrochemical windows, and good solubility for a wide range of substances [1,2]. Currently, there is a wide range of applications for ILs, such as separations [3], antibacterial [4,5], and porous materials [6,7]. Meanwhile, as a kind of luminescent material, rare earth is widely used in many fields due to its sharp line of absorption and emission spectrum, long excited state life, high color purity and low temperature quenching. Considering the good chemical activity and design ability of ionic liquid, ionic liquid as a matrix material has developed well in the field of rare earth luminescence. Recently, lanthanide complexes functionalized ionic liquid hybrid materials have aroused extensive interest of researchers $[8,9]$. However, the application of lanthanide-ILs hybrid material is limited because it is a challenge for functionalized ILs to be applied in solid devices and maintains their unique properties at the same time. It is surprising that ILs can be polymerized to form a polymer chain in which ions are somehow fixed but still have ionic features. Poly (ionic liquid)s (PILs), or polymerized ionic liquids, are polyelectrolyte that comprise a polymeric backbone and an ionic liquid (IL) species in monomer repeating units [10,11]. One simple way to synthesize the lanthanide-poly (ionic liquid)s is to doped the complexes into the long chain of the polymer. However, some obvious disadvantages, such as uneven distribution, difficulty of characterize and aggregation, will affect the practical application. So we prefer to select another way to synthesize the samples, which refers to the covalent or non-covalent bonding reaction and could be finished by introduction of ligand modified ionic liquid monomer.

Polyhedral oligomeric silsesquioxane (POSS) has an organic-inorganic hybrid nano-filler with a unique hollow cage structure, which contains silicon and oxygen $\left(-\mathrm{Si}_{8} \mathrm{O}_{12}\right)$ and eight variable organic side groups linkaged at each silicon vertex of the cage [12]. It has sparked a heated discussion due to its welldefined rigid inorganic silica-like framework and conveniently modifiable organic groups. POSS derivatives, which mean there are various organic groups attached to the

\footnotetext{
* Corresponding author. School of Material Science \& Engineering, University of Shanghai for Science and Technology, Shanghai, 200093, PR China. E-mail address:

liying@usst.edu.cn (Y.Li).
} 
Received 27 June 2019; Received in revised form 6 August 2019; Accepted 15 August 2019 Available online 17 August 2019

0143-7208/ @ 2019 Elsevier Ltd. All rights reserved.

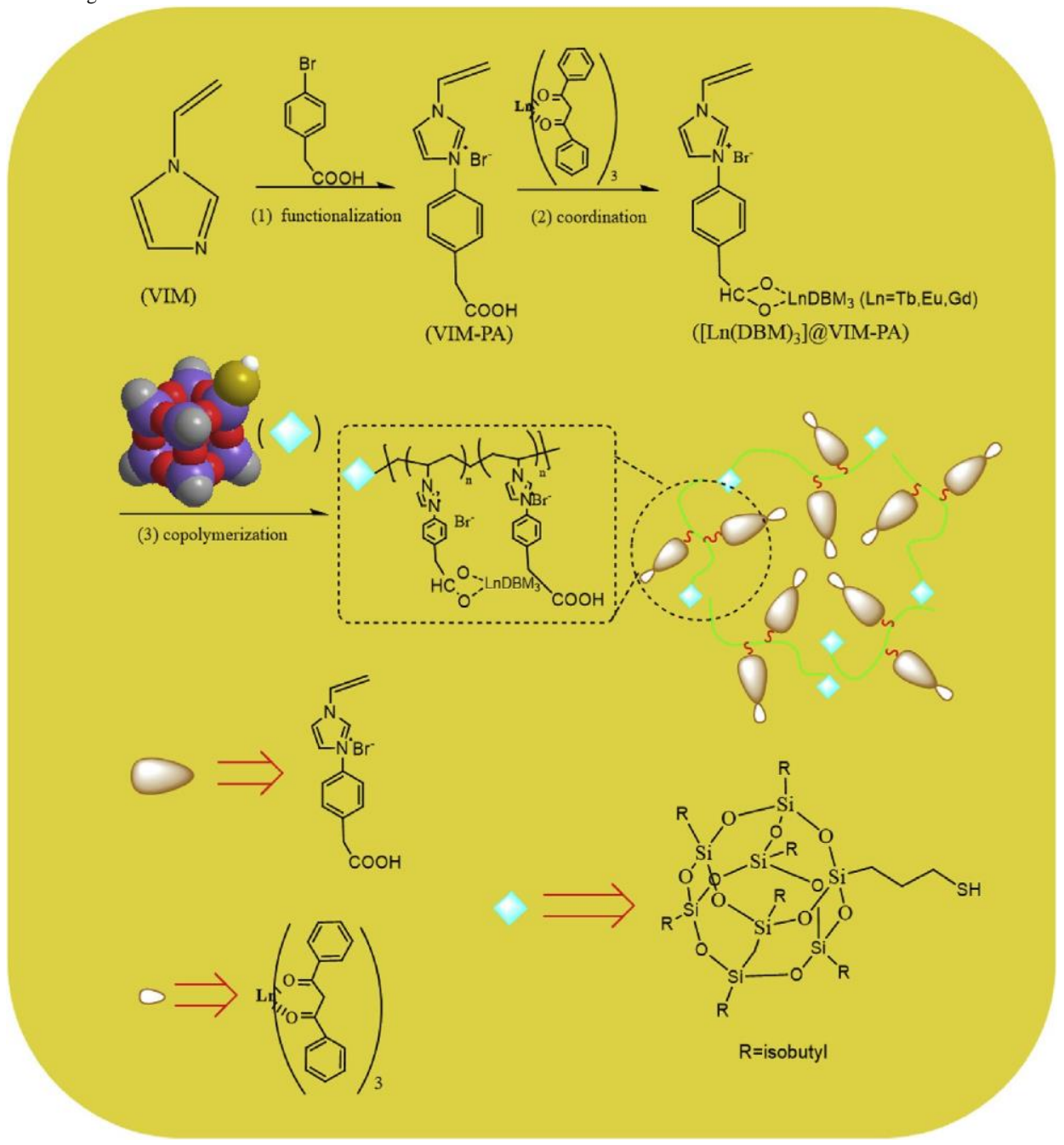

Scheme 1. Experimental process and schematic diagram of POSS-PVIM@ [Ln (DBM) $]$ ( $\mathrm{Ln}=\mathrm{Eu}(1), \mathrm{Tb}(2), \mathrm{Gd}(3))$.

backbone of POSS, can be tailored for various applications, such as coatings [13], tissue engineering scaffolds [14,15], porous materials [16,17], nanocomposites drug delivery [18], and self-assembled structures [19], etc. The lanthanide complex with POSS structure as a substrate has been reported and the $\mathrm{Si}-\mathrm{O}-\mathrm{Si}$ backbone with organic functionality at each of the eight corners can be easily introduced into a polymer chain by chemical modification or just by physical blending [20-23]. Consequently, the inorganic framework of POSS can impart superb thermostability and mechanical properties to polymeric hybrid materials [24,25].

Herein, we report a novel hybrid luminescent material obtained through the polymerization of POSS-SH with the chelates, which refer to the complex of the 1-Vinylimidazole (VIM) containing phenylacetic acid (PA) moieties in each of the repeating units with lanthanide (III) complex precursor [ $\mathrm{Ln}(\mathrm{DBM})_{3}$ ] $(\mathrm{DBM}=$ Dibenzoyl methane, $\mathrm{Ln}=\mathrm{Eu}, \mathrm{Tb}, \mathrm{Gd})$. Compared with [Ln $\left.(\mathrm{DBM})_{3}\right]$, a remarkable improvement in the luminescent behavior, photostability and thermostability, were achieved in the hybrid material POSS-PVIM@[Ln $\left.(\mathrm{DBM})_{3}\right](\mathrm{Ln}=\mathrm{Eu}, \mathrm{Tb}, \mathrm{Gd})$ (Scheme 1$)$. The second ligand cannot only expel water molecules to coordinate with lanthanide ions but also largely influence the microstructure which may accelerate energy transfer and thus improve the luminescence intensity and quantum efficiency of the final hybrid materials. Due to the red, green and blue emission can be achieved by the synthesized items, we can adjust the ratio of lanthanide (III) (Eu, Tb, Gd) so that the white emission $(\mathrm{CIE}=(0.32,0.27))$ can be achieved. What is more, the excellent luminescence performance depends on the effective energy transfer process from the ligand to the metal, which is affected by the interaction between the object molecule and the ligand or between the object molecule and the metal, then further affecting the luminescence intensity of the subject and thereby realizing the recognition of the object molecule by changes in luminescence intensity of the subject [26-29]. On accounting of the good luminescence property of POSS-PVIM@ [Eu (DBM) 3 , we consider using it for anion sensing research. The results show that the prepared samples can effectively monitor the dichromate ions with high sensitivity and selectivity, the detection limit of POSS-PVIM@[Eu $\left.(\mathrm{DBM})_{3}\right]$ to $\mathrm{Cr}_{2} \mathrm{O}_{7}^{2--}$ is $0.68 \mu \mathrm{M}$, indicating the hybrid material is feasible and reliable for anion sensing.

\section{Experimental}

\subsection{Synthetic procedures}

\subsubsection{Synthesis of VIM-PA}

1-Vinylimidazole $(0.101 \mathrm{~g}, 6.4 \mathrm{mmol})$ and 4-Bromophenylacetic Acid $(1.587 \mathrm{~g}, 7.4 \mathrm{mmol})$ was dissolved in ethanol $(10 \mathrm{~mL})$ in a roundbottom flask fitted with a condenser. Subsequently, the mixture was stirred at $80^{\circ} \mathrm{C}$ for $24 \mathrm{~h}$ under nitrogen atmosphere. After then, the reaction solution was precipitated from diethyl ether $(30 \mathrm{~mL})$, and the solid from filtration was dissolved in ethanol and precipitated from diethyl ether two times. The obtained white solid 
was dried under vacuum for $24 \mathrm{~h}$ at $50{ }^{\circ} \mathrm{C}$. (yield: $\left.65,1 \%\right) .{ }^{1} \mathrm{H}$ NMR $(600 \mathrm{MHz}$, $\left.\mathrm{CDCl}_{3}\right) \delta=9.723(\mathrm{~m}, 1 \mathrm{H}), 8.421(\mathrm{~d}, 1 \mathrm{H}), 8.101(\mathrm{~m}, 2 \mathrm{H}), 7.643(\mathrm{~d}, 2 \mathrm{H}), 7.410$ (d, 2H), $5.502(\mathrm{t}, 2 \mathrm{H}), 3.487(\mathrm{~s}, 1 \mathrm{H}), 1.342(\mathrm{t}, 2 \mathrm{H})$.

\subsubsection{Synthesis of $\left[\operatorname{Ln}(\mathrm{DBM})_{3}\right] @ \mathrm{VIM}-\mathrm{PA}(\mathrm{Ln}=\mathrm{Eu}, \mathrm{Tb}, \mathrm{Gd})$}

VIM-PA (0.0927 g, $0.3 \mathrm{mmol})$ was dissolved in ethanol $(20 \mathrm{~mL})$, and $\mathrm{NaOH}$ (12 mg, $0.3 \mathrm{mmol})$ was added. After sonication for $15 \mathrm{~min}, \mathrm{Eu}(\mathrm{DBM})_{3}(0.861$ $\mathrm{g}, 0.1 \mathrm{mmol}$ ) was added. The mixture was stirred at $65^{\circ} \mathrm{C}$ for $24 \mathrm{~h}$. After cooling to room temperature, the precipitate was collected by centrifugation and washed with ethanol and dried at $50{ }^{\circ} \mathrm{C}$ in vacuum overnight. The luminescence intensity of $\left[\mathrm{Ln}(\mathrm{DBM})_{3}\right] @$ VIM-PA reached a maximum when the ratio of VIM-PA to [ $\left.\mathrm{Ln}(\mathrm{DBM})_{3}\right]$ was 3:1 due to the difficulty of coordination of phenyl acetic acid with $\left[\mathrm{Ln}(\mathrm{DBM})_{3}\right]$.

2.1.3. Preparation and fluorescence sensing of POSS-PVIM@ $\left[\operatorname{Ln}(\mathrm{DBM})_{3}\right]$ POSS-SH (20 mg, $0.023 \mathrm{mmol}$ ) and AIBN ( $2 \mathrm{mg}, 0.122 \mathrm{mmol})$ in $20 \mathrm{~mL} \mathrm{~N}, \mathrm{~N}-$ dimethylformamide (DMF) were taken in a round bottom flask. After $1 \mathrm{~h}$ of nitrogen injection, [Ln (DBM) $)_{3} @$ VIM-PA (0.35 g, 0.299 mmol) was added. The bottom containing the reaction mixture was placed in an oil bath to carry out the polymerization reaction for $24 \mathrm{~h}$ at $90^{\circ} \mathrm{C}$. Then, the resulting mixtures were added into acetone to remove unreacted $\left[\mathrm{Ln}(\mathrm{DBM})_{3}\right] @$ VIM-PA monomer. Subsequent the solvent was removed by rotary evaporation and dried in vacuum. Finally, a yellow solid POSS-PVIM@ $\left[\mathrm{Ln}(\mathrm{DBM})_{3}\right](\mathrm{Ln}=\mathrm{Eu}(1)$, $\mathrm{Tb}$ (2), Gd (3)) was obtained. (yield: $60 \%$ ). Then the samples were put into 25 $\mathrm{mL}$ sealed container glass bottle with $6 \mathrm{~mL} \mathrm{~K}_{\mathrm{x}} \mathrm{M}\left(10^{-3} \mathrm{~mol} / \mathrm{L}\right)$ aqueous solution at room temperature $\left(\mathrm{M}^{\mathrm{x}-}=\mathrm{CO}_{3}{ }^{2-}, \mathrm{SO}_{4}{ }^{2-}, \mathrm{Cl}^{-}, \mathrm{Br}^{-}, \mathrm{NO}_{3}{ }^{-}, \mathrm{Cr}_{2} \mathrm{O}_{7}{ }^{2-}, \mathrm{CrO}_{4}{ }^{2-}\right.$, $\mathrm{MnO}_{4}^{-}$). After ultrasonic treatment for $5 \mathrm{~min}$, anion-incorporated suspensions were prepared for luminescence experiments. What is more, we studied the sensitivity of hybrid material to changes in anions concentration $(0 \mu \mathrm{M}-50 \mu \mathrm{M})$. $3 \mathrm{mg}$ of the sample was immersed in the different concentrations of anions solutions. The suspensions were then sonicated for $5 \mathrm{~min}$ for further luminescence measurements.

\subsubsection{Synthesis of POSS-PVIM@ $\left[\operatorname{Ln}(\mathrm{DBM})_{3}\right]$ polymer thin films}

The polymer films were prepared as follows: $3 \mathrm{mg}$ of POSSPVIM@[Ln $\left.(\mathrm{DBM})_{3}\right](\mathrm{Ln}=\mathrm{Eu}(1), \mathrm{Tb}(2), \mathrm{Gd}(3))$ and polyvinylpyrrolidone (PVP, $\left.100 \mathrm{mg}\right)$ were added into the mixed solution of $10 \mathrm{~mL} \mathrm{~N}, \mathrm{~N}$ - dimethylformamide (DMF) and $4 \mathrm{~mL}$ of deionized water. The mixture was further stirred for $2 \mathrm{~h}$ at $50{ }^{\circ} \mathrm{C}$ under refluxing. Then the mixed solution placed in a Petri dish was heated at $80{ }^{\circ} \mathrm{C}$ for $6 \mathrm{~h}$. The film was finally obtained using a direct coating method.

\subsection{Materials and instruments}

$\mathrm{LnCl}_{3} * 6 \mathrm{H}_{2} \mathrm{O}$ was prepared by dissolving lanthanide oxide (aladding, $99 \%$ ) in hydrochloric acid followed by evaporation and vacuum drying. Other materials (A.R) and reagents (A.R) were purchased from professional reagent brand and used without further purification. FTIR spectra were collected on a Nexus 912 AO446 spectrophotometer using $\mathrm{KBr}$ pellets in the range of 4000$400 \mathrm{~cm}^{-1} .{ }^{1} \mathrm{H}$ NMR spectra of all the synthesized samples in $\mathrm{D}_{6}$-DMSO were recorded using an Ascend 400 spectrometer. XRD measurements were performed on an X-ray powder diffractometer (BRUKER D8 Focus). X-ray photoelectric spectrometry (XPS) was determined using PHI-5000 versaprobe to reveal the coordination interaction. Excitation and emission spectra of the samples were recorded on a RF-5301PC spectrophotometer using a $450 \mathrm{~W}$ xenon lamp as the excitation source. Samples for thermogravimetry (TG) studies were analyzed using Pyris 1 TGA Instruments at a heating rate of $10{ }^{\circ} \mathrm{C}$ $\min ^{-1}$ under a nitrogen atmosphere. Ultraviolet-visible (UV-vis) spectroscopy was measured by Lambda 750 with the wavelength range from 200 to $800 \mathrm{~nm}$.

\section{Results and discussion}

Powered samples [Ln $\left.(\mathrm{DBM})_{3}\right] @$ VIM-PA were first synthesized by dissolving VIM-PA, which was prepared by adding the 1-vinylimidazole and 4-bromophenylacetic acid into ethanol at $80{ }^{\circ} \mathrm{C}$ for $24 \mathrm{~h}$, and $\mathrm{Ln}(\mathrm{DBM})_{3}$ in ethanol in presence of $\mathrm{NaOH}$ at $65^{\circ} \mathrm{C}$ for $24 \mathrm{~h}$. The product then polymerized with POSS-SH and AlBN acted as initiator at $80{ }^{\circ} \mathrm{C}$ for $24 \mathrm{~h}$, POSS-PVIM@ $\left[\mathrm{Ln}(\mathrm{DBM})_{3}\right](\mathrm{Ln}=\mathrm{Eu}(1), \mathrm{Tb}(2), \mathrm{Gd}(3))$, a novel hybrid material with good stability and brilliant fluorescence performance, were finally obtained. What is more, the luminescent films were then obtained by a solution casting method and can be easily peeled from the Petri dish and denoted as PVP@POSS-PVIMLn. Due to the good characteristic luminescence of the prepared samples, the proportion of $\mathrm{Eu}^{3+}, \mathrm{Tb}^{3+}$ and $\mathrm{Gd}^{3+}$ and the excitation wavelength were adjusted, we finally obtained the white light emission under $300 \mathrm{~nm} \mathrm{UV} \mathrm{(CIE}(0.32,0.27)$ and carried out anionic sensing. And it exhibited obvious luminescent quenching, especially in the case of $\mathrm{Cr}_{2} \mathrm{O}_{7}{ }^{2-}$ existence, a highly toxic hexavalent chromium ion, which can lead to gastrointestinal disease and skin lesions even cancer.

\subsection{Structural characterization of POSS-PVIM@ $\left[\operatorname{Ln}(\mathrm{DBM})_{3}\right]$}

$\left[\mathrm{Eu}(\mathrm{DBM})_{3}\right] @$ VIM-PA was synthesized with dissolving Eu $(\mathrm{DBM})_{3}$ and VIM-PA in ethanol. The carboxyl group of VIM-PA coordinated with $\mathrm{Eu}^{3+}$ ion as a co-ligand and POSS-PVIM@[Eu $\left.(\mathrm{DBM})_{3}\right]$ was prepared via the copolymerization of POSS-SH and [Eu (DBM) $)_{3} @$ VIM-PA in DMF under $\mathrm{N}_{2}$ atmosphere(Scheme 1).The FT-IR spectra of [Eu (DBM) $)_{3} @$ VIM-PA and 1 show the coordination behavior of $\mathrm{Eu}(\mathrm{DBM})_{3}$ with VIM-PA (Fig. 1). The band centered $1100 \mathrm{~cm}^{-1}$ was due to the existence of $\mathrm{Si}-\mathrm{O}-\mathrm{Si}$. The absorption band at $1690 \mathrm{~cm}^{-1}$ was assigned to C]O stretching vibrations of benzoic acid, which shift to $1630 \mathrm{~cm}^{-1}$ in the 1 , this red shift is attributed to the coordination of carboxyl group to $\mathrm{Eu}^{3+}$. The bands centered near $1555 \mathrm{~cm}^{-1}$ and $1395 \mathrm{~cm}^{-1}$ in the spectra of 1 are attributed to the asymmetric and symmetric vibrations of the carboxyl group, respectively [30]. Meanwhile, the bands at $1650 \mathrm{~cm}^{-1}$ ascribed to $-\mathrm{C}] \mathrm{C}$ - and at $2552 \mathrm{~cm}^{-1}$ ascribed to the sulphydryl disappeared, respectively, indicating the polymerization reaction of POSS-SH and VIM. In addition, the FT-IR spectra of 2 and 3 (Fig. S1) were similar, further confirming their isostructure.

The as-prepared POSS-PVIM@ [ $\left.\operatorname{Ln}(\mathrm{DBM})_{3}\right]$ was also monitored by 11 HNMR spectra and X-ray photoelectron spectroscopy. HNMR spectra of VIM-PA (Fig. S2a) exhibited characteristic peaks $(\delta=9.723(\mathrm{~m}, 1 \mathrm{H}), 8.421(\mathrm{~d}$, $1 \mathrm{H}), 8.101(\mathrm{~m}, 2 \mathrm{H}), 7.643(\mathrm{~d}, 2 \mathrm{H}), 7.410(\mathrm{~d}, 2 \mathrm{H}), 5.502(\mathrm{t}$, $2 \mathrm{H}), 3.487(\mathrm{~s}, 1 \mathrm{H}), 1.342(\mathrm{t}, 2 \mathrm{H}))$, indicating the formation of the final

$\mathrm{c}$

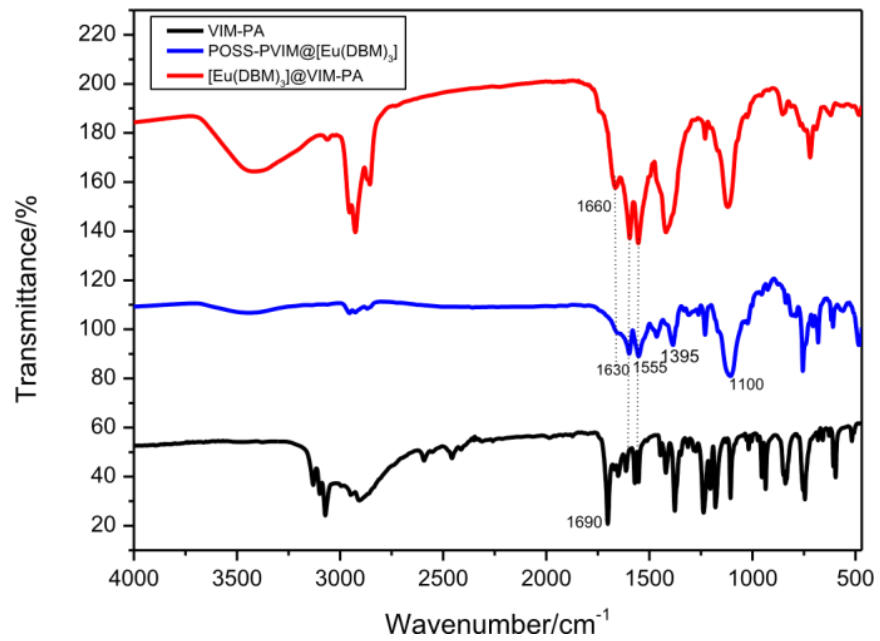


Fig. 1. FT-IR spectra of VIM-PA, 1 and [Eu (DBM) 3 @ VIM-PA

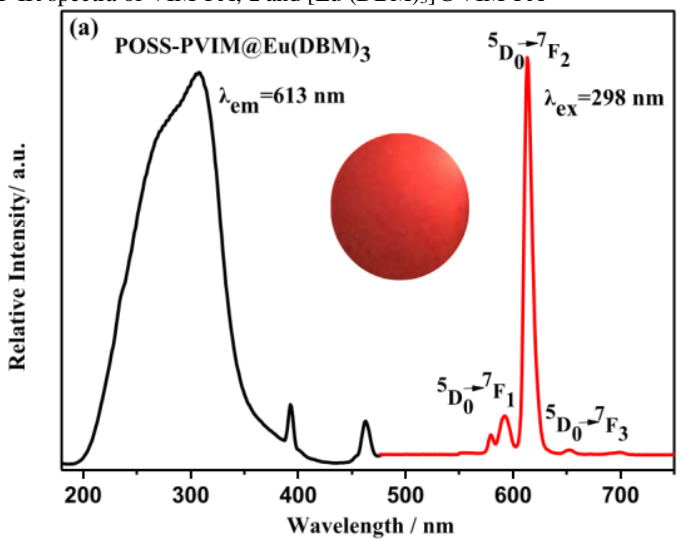

Fig. S5 shows the thermal analysis curves of pure complex Eu $(\mathrm{DBM})_{3}(\mathrm{a})$

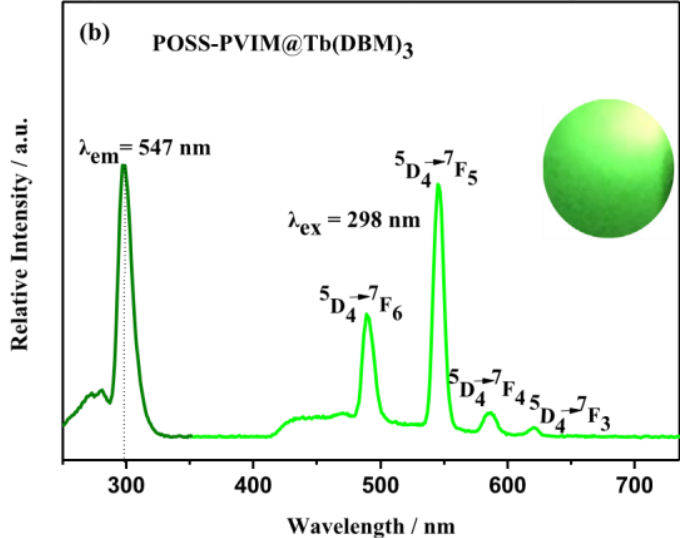

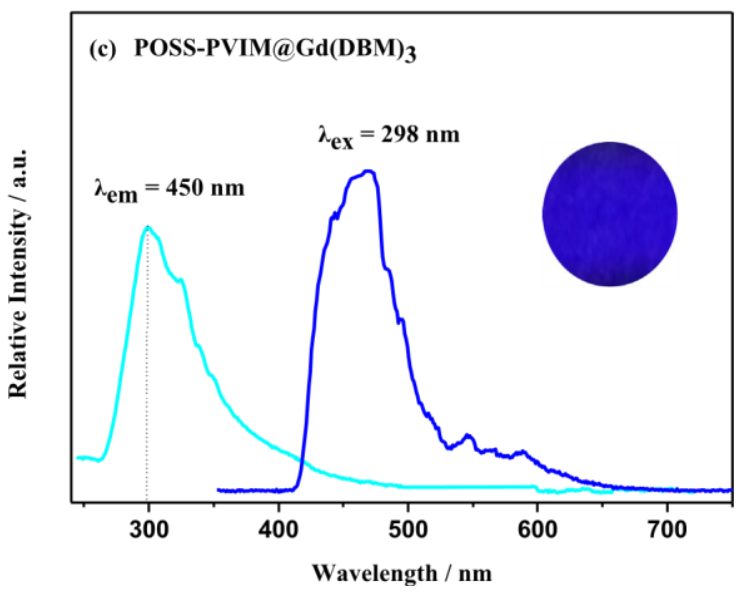

Fig. 2. Excitation and emission spectra of 1 (a), 2 (b) and 3 (c); the inset show the corresponding photoluminescence colors under UV-light irradiation of $298 \mathrm{~nm}$. (For interpretation of the references to color in this figure legend, the reader is referred to the Web version of this article.) product. And the spectrum of 1 shows the signals at $8.261 \mathrm{ppm}$ and $7.660 \mathrm{ppm}$, corresponding to the peripheral hydrogen of imidazole group and benzene ring of the long chain, respectively. What is more, the peaks at $0.870 \mathrm{ppm}$ correspond to the $-\mathrm{CH}_{2}$ and $-\mathrm{CH}_{3}$ groups of the isobutyl moiety directly attached to the silicon atom at the rest seven corners of POSS unit, which is consistent with the structure of the synthesized sample.

(Fig. S2b) X-ray photoelectron spectroscopy (XPS) has further revealed the coordination interaction of POSS-PVIM@ [Ln $\left.(\mathrm{DBM})_{3}\right]$. As shown in full XPS spectra (Fig. S3a), the peak appearing at $1106.5 \mathrm{eV}$ ascribed to $\mathrm{Eu}^{3+} 3 \mathrm{~d}$ confirm the introduction of $\mathrm{Eu}^{3+}$ in the 1. The O1s XPS spectra of VIM-PA and 1 are enlarged in Fig. S3b. It can be observed that there is a higher binding energy $(532.1 \mathrm{eV})$ for the O1s peak compared to the VIM-PA $(531.1 \mathrm{eV})$, which is ascribed to the formation of Ln-O coordination bonds [31]. This phenomenon can be attributed to the introduction of lanthanide complexes, which can bond to carboxylic groups from the phenylacetic acid ligand, leading to a decrease in the electron density of $\mathrm{O}$ atoms, thus arise a shift in the $\mathrm{O} 1 \mathrm{~s}$ peak to the higher binding energy.

The PXRD pattern of 1 is shown in Fig. S4. It can be clearly seen that there is a sharp peak at $2 \theta=8.1^{\circ}$ corresponding to the POSS cage, which indicates that the sample has good crystallinity, suggesting that the introduction of lanthanide complex does not change the crystalline phase structure. Moreover, broad peak at $17 \sim 27^{\circ}$ is due to the accumulation and winding of the long chain structure formed by the random copolymerization of POSS with lanthanide functional ionic liquid monomers. and 1 (b). The TGA diagram of Eu (DBM) $)_{3}$ shows two main pyrolysis processes with maximum weight mass loss rate at $200{ }^{\circ} \mathrm{C}$ and $450{ }^{\circ} \mathrm{C}$, respectively. The first stage (heat loss: cal. $4.5 \%$ ) corresponds to the removal of water molecules and residual solvents, and the second stages (heat loss: cal. $80.2 \%$ ) can be attributed to decomposition of the DBM ligand. A plateau is seen at about $650{ }^{\circ} \mathrm{C}$, implying the formation of stable $\mathrm{Eu}_{2} \mathrm{O}_{3}$ (cal. 18.20\%), which is in good consistent with the calculated amount for $\left[\mathrm{Eu}(\mathrm{DBM})_{3}\right] \cdot 2 \mathrm{H}_{2} \mathrm{O}$ (cal. 17.79\%). Compared with the curve of Eu $(\mathrm{DBM})_{3}$, the totally mass loss of hybrid materials 1 is $56 \%$. There are two main steps for the decomposition of 1 , the first step at $250-350{ }^{\circ} \mathrm{C}$ corresponding to the decomposition of DBM ligand. The second step occurs from $400{ }^{\circ} \mathrm{C}$ to $600{ }^{\circ} \mathrm{C}$, which can be ascribed to decompositions of the long chain $\mathrm{Si}-\mathrm{O}-\mathrm{Si}$ structure of poly (ionic liquid). It should be noted that the decomposition temperature $\left(255^{\circ} \mathrm{C}\right)$ of 1 is higher than that of $\mathrm{Eu}(\mathrm{DBM})_{3}\left(210^{\circ} \mathrm{C}\right)$, which can indicates that the thermal stability of 1 is significantly improved.

\subsection{Photoluminescence properties of the hybrids POSS-PVIM@ [Ln $\left.(\mathrm{DBM})_{3}\right]$}

The luminescence properties of the three $\mathrm{Ln}^{3+}$ modified complexes in the solid state were investigated at room temperature. The excitation and emission spectra of all the samples are displayed in Fig. 2. As can be clearly seen that the excitation spectra of POSS-PVIM@[Ln $\left.(\mathrm{DBM})_{3}\right](\mathrm{Ln}=\mathrm{Eu}(\mathrm{a}), \mathrm{Tb}(\mathrm{b}), \mathrm{Gd}(\mathrm{c}))$ are all dominated by the absorption bands located at about $298 \mathrm{~nm}$. The emission spectra of POSS-PVIM@ [Ln 

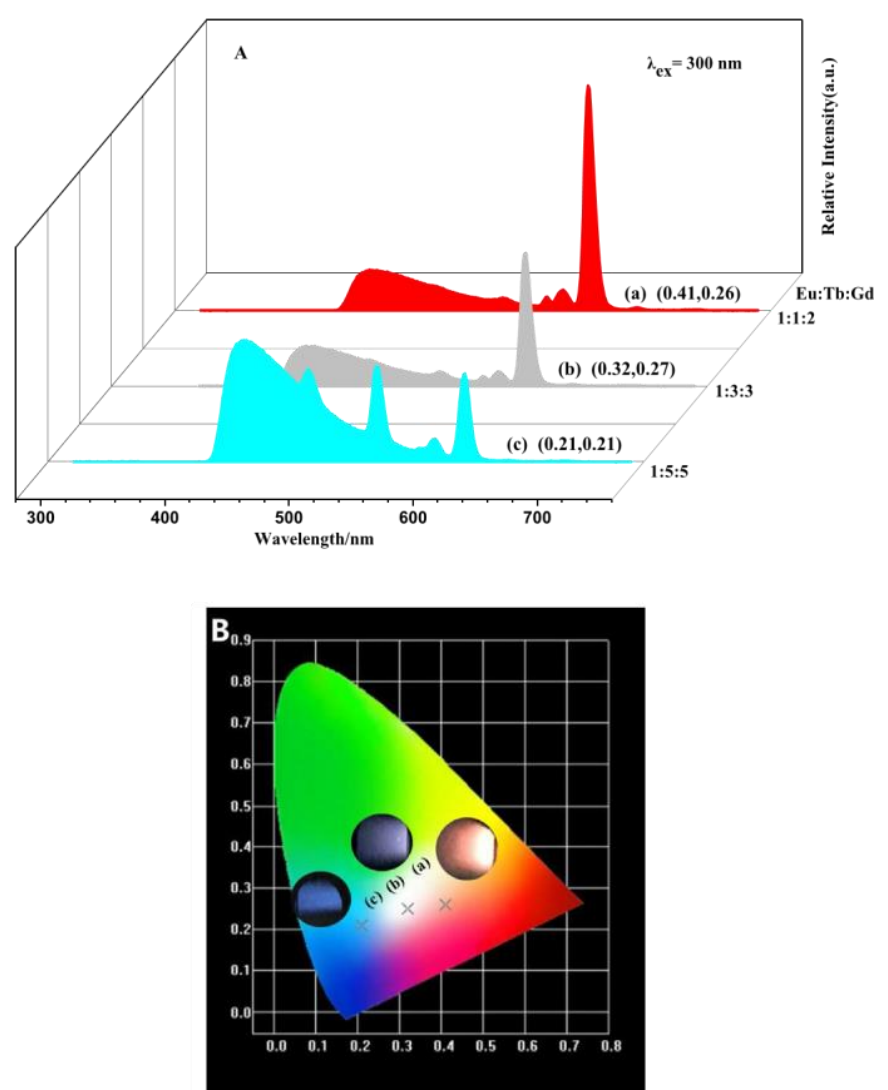

Fig. 3. (A) The emission spectra of POSS-PVIM@ $\left[\operatorname{Ln}(\mathrm{DBM})_{3}\right]$ under excitation at $300 \mathrm{~nm}$, where the $\left[\mathrm{Eu}^{3+}\right]:\left[\mathrm{Tb}^{3+}\right]:\left[\mathrm{Gd}^{3+}\right]$ concentration ratios are: (a) [1:1:2], (b) [1:3:3], (c) [1:5:5]. (B) The corresponding CIE chromaticity diagram.

$\left.(\mathrm{DBM})_{3}\right]_{\text {are }}$ mainly obtained by using the appreciated wavelength as the excitation source to show the corresponding characteristic emission peaks. In the sample 1 (Fig. 2a), the excitation spectrum obtained by monitoring the ${ }^{5} \mathrm{D}_{0} \rightarrow{ }^{7} \mathrm{~F}_{2}$ transition at $613 \mathrm{~nm}$ displays a broad band in the range from $\lambda=260$ $350 \mathrm{~nm}$, which can be attributed to the absorption of the ligand. The emission spectrum of 1 displays five sharp peaks located at 580, 592, 613, 651 and 703 $\mathrm{nm}$, which can be assigned to ${ }^{5} \mathrm{D}_{0} \rightarrow{ }^{7} \mathrm{~F}_{\mathrm{J}}(\mathrm{J}=0-4)$ transitions of $\mathrm{Eu}^{3+}$ respectively. It can be clearly observed that the emission spectra given in Fig. 2 (a) are dominated by the intense ${ }^{5} \mathrm{D}_{0} \rightarrow{ }^{7} \mathrm{~F}_{2}$ transition at $613 \mathrm{~nm}$. The peaks around 592 $\mathrm{nm}\left({ }^{5} \mathrm{D}_{0} \rightarrow{ }^{7} \mathrm{~F}_{1}\right)$ and $613 \mathrm{~nm}\left({ }^{5} \mathrm{D}_{0} \rightarrow{ }^{7} \mathrm{~F}_{2}\right)$ obtain orange-red and red colors, respectively. It is well known that the ${ }^{5} \mathrm{D}_{0} \rightarrow{ }^{7} \mathrm{~F}_{2}$ transition is a typical electric dipole transition and strongly varies with the local symmetry of $\mathrm{Eu}^{3+}$ ions, while the ${ }^{5} \mathrm{D}_{0} \rightarrow{ }^{7} \mathrm{~F}_{1}$ transition corresponds to a parity-allowed magnetic dipole transition, which is practically independent of the host material. Generally, the center $\mathrm{Eu}^{3+}$ ions can be used as a probe for the crystal field environments by the comparison of the intensity of the ${ }^{5} \mathrm{D}_{0} \rightarrow{ }^{7} \mathrm{~F}_{1}$ transition with that of the ${ }^{5} \mathrm{D}_{0} \rightarrow{ }^{7} \mathrm{~F}_{2}$ transition, because the red/orange ratio $\left({ }^{5} \mathrm{D}_{0} \rightarrow{ }^{7} \mathrm{~F}_{2}{ }^{5} \mathrm{D}_{0} \rightarrow{ }^{7} \mathrm{~F}_{1}\right)$ is sensitive to the structural change in the vicinity of $\mathrm{Eu}^{3+}$ ions. Therefore, the much stronger intensity of the ${ }^{5} \mathrm{D}_{0} \rightarrow{ }^{7} \mathrm{~F}_{2}$ transition than those of other transitions in the emission spectra indicate that the $\mathrm{Eu}^{3+}$ ion site is situated in an environment without a center of inversion symmetry and the hybrid even has good color purity [32].

In addition, it can be seen that ${ }^{5} \mathrm{D}_{0} \rightarrow{ }^{7} \mathrm{~F}_{2}$ transition shows the strongest emission among these transitions and the calculated intensity red/orange ratio of $\mathrm{I}_{02} / \mathrm{I}_{01}\left({ }^{5} \mathrm{D}_{0} \rightarrow{ }^{7} \mathrm{~F}_{2} /{ }^{5} \mathrm{D}_{0} \rightarrow{ }^{7} \mathrm{~F}_{1}\right)$ is 10.6 , suggesting the chemical environment around europium ions is in low symmetry. There is no ligand centered emission in the emission spectrum, indicating that the energy transfer from ligand to $\mathrm{Eu}^{3+}$ is effective, and the CIE diagram located at $(0.63,0.28)$ can also prove the red emission of 1 (Fig.
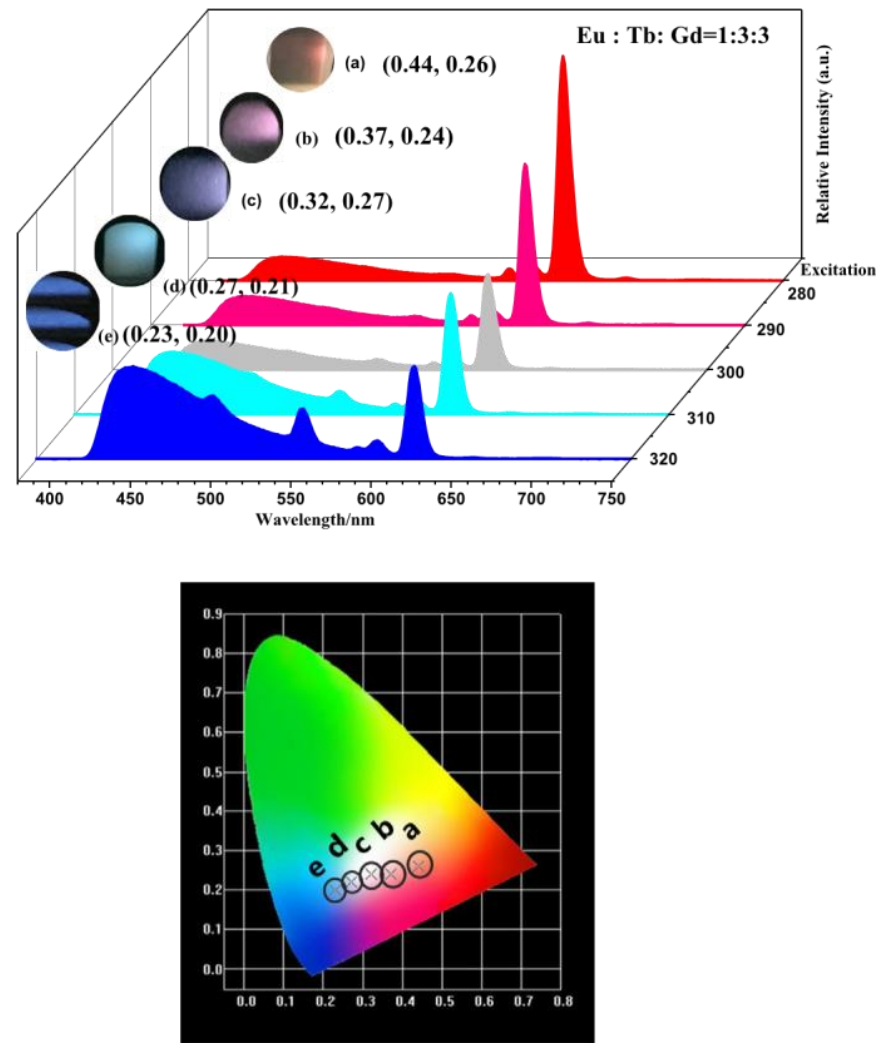

Fig. 4. Emission spectra of Eu $\mathrm{u}_{0.14} \mathrm{~Tb}_{0.43} \mathrm{Gd}_{0.43} @ \mathrm{POSS}$-PVIM with excitation wavelengths varying from 280 to $320 \mathrm{~nm}$ and the corresponding CIE chromaticity diagram.

S6a). Additionally, 1 shows a strong red luminescence, which can be clearly observed by the naked eye under the UV-light irradiation, as shown in the inset of Fig. 2a, indicating the occurrence of the antenna effect.

For further investigation on the photoluminescence properties of 1 , we measured the luminescence lifetime decay curves of $\left[\mathrm{Eu}(\mathrm{DBM})_{3}\right]$ and 1 at room temperature (Fig. S7), the resulting lifetimes and quantum efficiency are given in Table S1. The typical decay curve of 1 can be described as a single exponential $\left(\ln \left(\mathrm{S}(\mathrm{t}) / \mathrm{S}_{0}\right)=-\mathrm{k}_{1} \mathrm{t}=-\mathrm{t} / \mathrm{\tau}\right)$, indicating that the center $\mathrm{Eu}^{3+}$ ions occupy the same average coordination environment. It can be clearly seen that the fluorescence lifetime data of hybrid $1(\tau=0.428 \mathrm{~ms})$ is longer than that of pure complex $(\tau=0.085 \mathrm{~ms})$, suggesting that the introduction of organic polymeric chain enhance the luminescence stability of the whole system, and ionic liquid-assisted ligand improve the coordination saturation of $\mathrm{Ln}^{3+}$ while the fluorescence intensity of 1 increased compared to that of $\left[\mathrm{Eu}(\mathrm{DBM})_{3}\right]$. The quantum efficiency mainly depends on the values of two factors: lifetimes and red/orange ratio $\left(\mathrm{I}_{02} / \mathrm{I}_{01}\right)$. As can be clearly seen from Table $\mathrm{S} 1$, the quantum efficiency of $1(38 \%)$ is also much higher than that of $\mathrm{Eu}(\mathrm{DBM})_{3}(11 \%)$, which indicates that the introducing of polymeric chain not only enhances the luminescent intensities of the hybrid, but also extends the lifetimes and further improve the quantum efficiencies.

Fig. $2 \mathrm{~b}$ shows the excitation spectrum of $\mathrm{Tb}^{3+}$ sample 2 monitored by the emission wavelength at $545 \mathrm{~nm}$. The excitation spectrum consists of a dominant band centered at $298 \mathrm{~nm}$, which can be mainly ascribed to the transitions involving the $\pi-\pi^{*}$ states of organic unite VIM-PA. It can be seen from the emission spectrum of 2 that there are four sharp lines locating at 491, 545, 585, $623 \mathrm{~nm}$, which could be assigned to the ${ }^{5} \mathrm{D}_{4} \rightarrow{ }^{7} \mathrm{~F}_{6},{ }^{5} \mathrm{D}_{4} \rightarrow{ }^{7} \mathrm{~F}_{5},{ }^{5} \mathrm{D}_{4} \rightarrow{ }^{7} \mathrm{~F}_{4},{ }^{5} \mathrm{D}_{4} \rightarrow{ }^{7} \mathrm{~F}_{3}$, transitions of $\mathrm{Tb}^{3+}$,respectively. The emission maximum at $545 \mathrm{~nm}$ contributes to the green-emitting color, and the CIE chromaticity coordinates for 2 locates 

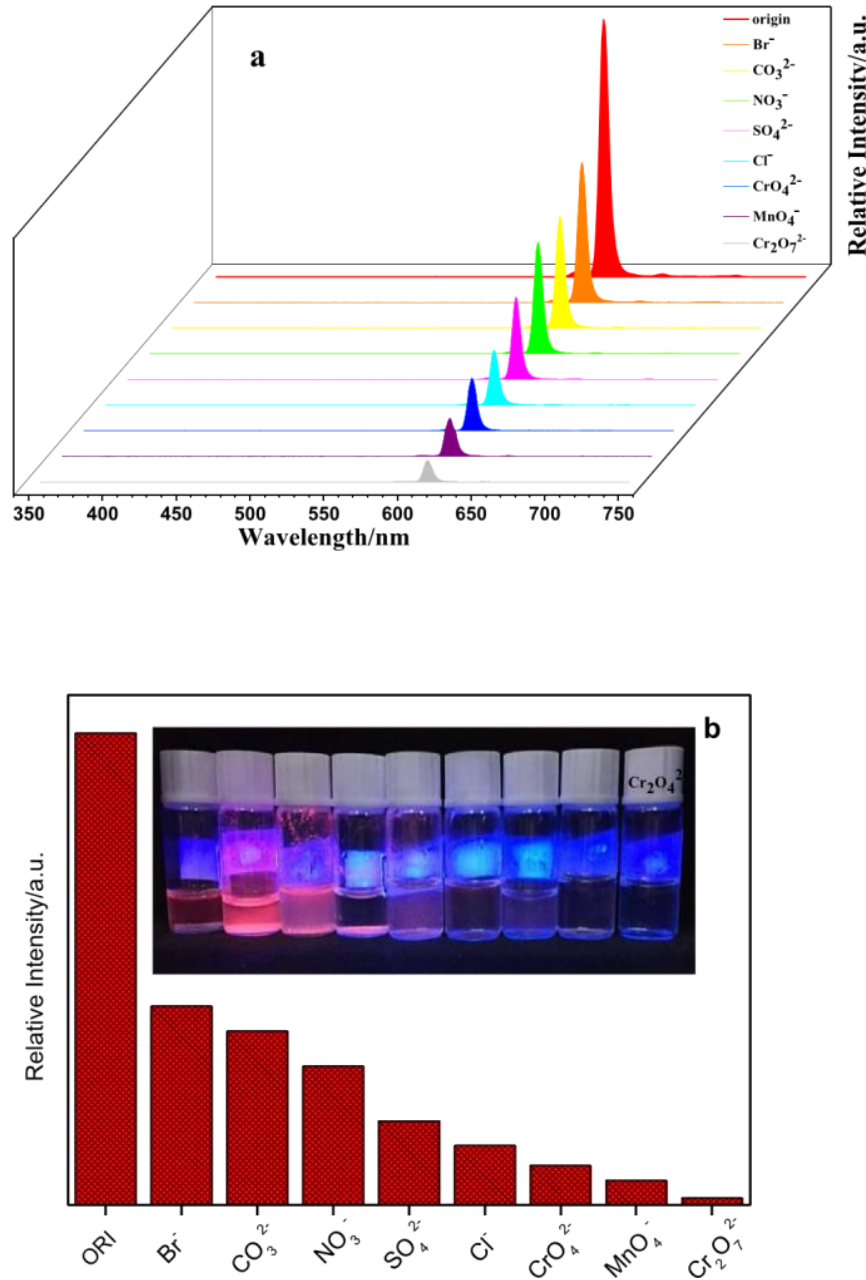

Fig. 5. The emission spectrum (a) and (b) the luminescent intensity of 1 interacting with different anions. $\left(\lambda_{\mathrm{ex}}=300 \mathrm{~nm}\right)$.

in light green regions, as shown in Fig. S6b. In addition, a small broad band centered at about $450 \mathrm{~nm}$ appears in the emission spectrum of hybrid 2, demonstrating the ligand in POSS-PVIM@ $\left[\mathrm{Tb}(\mathrm{DBM})_{3}\right]$ could not completely sensitize the luminescence of $\mathrm{Tb}^{3+}$. Furthermore, the energy level difference between the triple state energy level $\left(20520 \mathrm{~cm}^{-1}\right)$ of DBM and the resonance energy level of $\mathrm{Tb}^{3+}\left({ }^{5} \mathrm{D}_{4}, 20400 \mathrm{~cm}^{-1}\right)$ is less than $2500 \mathrm{~cm}^{-1}$, which does not conform to the empirical rule of Latva [33] $\left(\Delta \mathrm{e}^{2}={ }^{1} \mathrm{~T}-{ }^{5} \mathrm{D}_{4}\left(\Delta \mathrm{e}^{2}=2500-4500 \mathrm{~cm}^{-1}\right.\right.$, the energy transfer between ligand and $\mathrm{Ln}^{3+}$ could occur effectively). Therefore, the luminescence emission of hybrid 2 is mainly due to the energy transfer between modified ionic liquid ligand and $\mathrm{Tb}^{3+}$. Whereas, for POSS-PVIM@ [Gd $\left.(\mathrm{DBM})_{3}\right]$, the ligand-centered emission at $450 \mathrm{~nm}$ is obviously observed in Fig. 2c. Due to the first excited state of $\mathrm{Gd}^{3+}\left({ }^{6} \mathrm{P}_{7 / 2}=32150 \mathrm{~cm}^{-1}\right)$ is too high to be sensitized by ligand and the energy gap $\left(\Delta \mathrm{E}^{2}\right)$ between $\mathrm{Gd}^{3+}$ and ligand does not conform to the Latva's empirical rule, $\mathrm{Gd}^{3+}$ cannot be sensitized effectively by organic ligands. The emission spectrum of 3 exhibits a broad peak centered at $472 \mathrm{~nm}$ when it is excited by the wavelength of $298 \mathrm{~nm}$ (Fig. 2c), which locates in the blue region (Fig. S6c), can be ascribed to $\pi-\pi^{*}$ transition of the ligand. Subsequently, we incorporated polyvinylpyrrolidone (PVP) into DMF solution of POSS-PVIM@ $\left[\operatorname{Ln}(\mathrm{DBM})_{3}\right]$ with magnetic stirring under $50{ }^{\circ} \mathrm{C}$ for $2 \mathrm{~h}$, and then the transparent polymer film was obtained by heating and drying the solvent at $80{ }^{\circ} \mathrm{C}$. Since PVP acts as a physical matrix, polymerization reaction does not change the photoluminescence mechanism. It is well known that the energy is transferred from the triplet state of ligands in the lanthanide materials to the center ion, which raises the $4 \mathrm{f}$ electron of the center ions to the excited energy levels. So the excited energy levels of the organic ligand transferring subsequently to the lanthanide ions' resonant excited levels yield a light emission. Due to the long chain structure of poly (ionic liquid) and the rigid framework of $\mathrm{Si}-\mathrm{O}$ in polyhedral oligomeric silsesquioxane, POSSPVIM@[Ln $\left.(\mathrm{DBM})_{3}\right]$ has good film-forming and formability. Three kinds of polymer films show their characteristic transition emissions respectively (red (Fig. 2a), green (Fig. 2b) and blue (Fig. 2c) colors) under the excitation at 298 $\mathrm{nm}$. Among the lanthanide ions, the $\mathrm{Eu}^{3+}$ and $\mathrm{Tb}^{3+}$ ions are two of the most important luminescent activators which are most attractive due to their corresponding strong red and green emissions, respectively. In addition, the hybrid POSS-PVIM@ $\left[\mathrm{Gd}(\mathrm{DBM})_{3}\right]$ can be treated as a blue-emitter, in which the organic ligand can emit blue light under ultraviolet. Considering that three kinds of light emitters are all exhibiting the primary colors (red, green and blue), it is expected that we can obtain the tunable white emission with the regulation of the proportion of $\mathrm{Eu}^{3+}, \mathrm{Tb}^{3+}$ doped into $\mathrm{Gd}^{3+}$-based compounds [34-36].

White luminescent materials can offer the potential for more sensitive stimuli-responsive properties due to the multi-spectrum chromism. Therefore, a serious of co-doped poly (ionic liquid) are prepared by immersing $\mathrm{Eu}^{3+}, \mathrm{Tb}^{3+}$ and $\mathrm{Gd}^{3+}$ complex into the mixed DMF solution of POSS-SH and AIBN for 24 h. Further investigations on how to modulate the hybrids emission by changing the stoichiometry of the three lanthanide chromophores (red, green and blue) are measured. The emission color has a change from red to nattier blue while the ratio of $\mathrm{Eu}^{3+}, \mathrm{Tb}^{3+}, \mathrm{Gd}^{3+}$ changed, which refer to $\mathrm{Eu}^{3+}: \mathrm{Tb}^{3+}$ :

$\mathrm{Gd}^{3+}=1: 1: 2,1: 3: 3,1: 5: 5$, as shown in Fig. 3. Moreover, titration of the $\mathrm{Eu}^{3+} / \mathrm{Tb}^{3+} / \mathrm{Gd}^{3+}$ complex molar fraction can lead to a series of hybrid materials with a broad spectrum of emission including white light under UV irradiation. The photoluminescence color of Ln@POSSPVIM $\left(\mathrm{Eu}^{3+}: \mathrm{Tb}^{3+}: \mathrm{Gd}^{3+}=1: 3: 3\right)$ can be tuned from light red, pink, and warm white to cyan gradually by changing the excitation wavelength from 280 to $320 \mathrm{~nm}$ (Fig. 4). Interestingly, as the excitation wavelength increased, the intensity of red light decreased and the intensity of green light increased, possibly because the energy transfer between the ligand and $\mathrm{Ln}^{3+}$ was affected. The corresponding $\mathrm{CIE}$ chromaticity diagram under the different excitation wavelengths (280-320 nm) was shown in the inset of Fig. 4. Along with the increase of the excitation wavelength from 280 to 300 $\mathrm{nm}$, we can observe the luminescence intensity of 3 becomes intense obviously and the decreased red emission of $\mathrm{Eu}^{3+}$, thus causing the shift in the point of emission spectra in the CIE chromaticity diagram from light red (c: $x=0.44$ and $y=0.26)$ to white $(\mathrm{c}: \mathrm{x}=0.32$ and $\mathrm{y}=0.27)$ and cyan $(\mathrm{c}: \mathrm{x}=0.23$ and $\mathrm{y}=$ 0.20 ), respectively. It can be clearly seen when excited by $300 \mathrm{~nm}$, the sample emits the white emission and the corresponding CIE chromaticity coordinate (c: $\mathrm{x}=0.32$ and $\mathrm{y}=0.27$ ) locates in the white light region. 


\subsection{Chemical sensing properties of POSS-PVIM@ $\left[\mathrm{Eu}(\mathrm{DBM})_{3}\right]$}

From the aforementioned luminescent properties results of all the materials, the functionalized polymeric ligand could effectively sensitize the luminescence of $\mathrm{Eu}^{3+}$ and $\mathrm{Tb}^{3+}$, particularly the $\mathrm{Eu}^{3+}$ ion. Moreover, hybrid 1 exhibits longer lifetime and quantum efficiency than that of pure complex Eu $(\mathrm{DBM})_{3}$ (Table S1). Therefore, we choose 1 for further exploring the subsequent sensing behavior of different anions. In order to study the Photoluminescence stability of the sample, we immersed the samples 1 in a series of aqueous solutions with different $\mathrm{pH}$ value (4.0-9.0) to investigate the stability of hybrid in the emulated environment. The results (Fig. S8) revealed that the hybrid had a stable luminescence property under different $\mathrm{pH}$ conditions. Additionally, the sample has been placed in the Petri dish for several days and it can be clearly found that there was no obvious change in fluorescence intensity. As we expected, the good water-stability and pHbased tolerance of 1 provide the basis for the detection of anions in the water environment. What is more, we have investigated the structural stability of 1 in

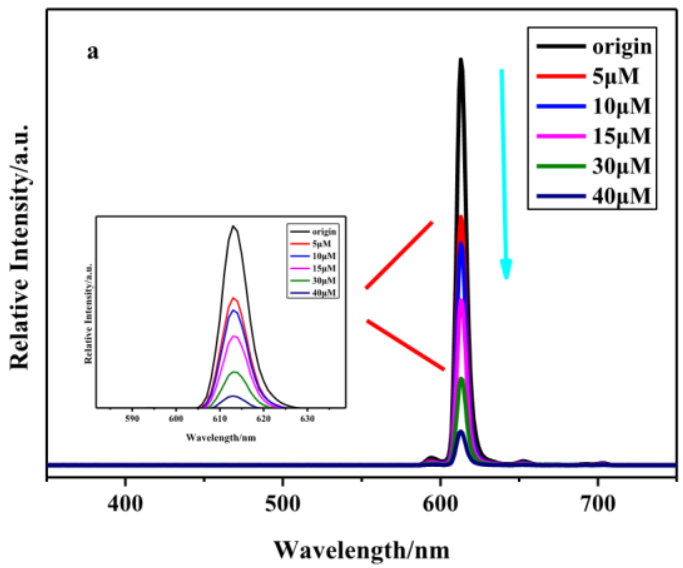

intensity at the wavelength of $613 \mathrm{~nm}$, which is ascribed to the ${ }^{5} \mathrm{D}_{0} \rightarrow{ }^{7} \mathrm{~F}_{2}$ transition of $\mathrm{Eu}^{3+}$. As shown in Fig. 5a, the characteristic red emission of $\mathrm{Eu}^{3+}$ is weakened in aqueous solution with different anions. Moreover, it is worth noting that $\mathrm{Cr}_{2} \mathrm{O}_{7}^{2--}$ can quench the intensity remarkably. We can also see the characteristic emission of $\mathrm{Eu}^{3+}$ ascribed to ${ }^{5} \mathrm{D}_{0} \rightarrow{ }^{7} \mathrm{~F}_{2}$ transition decreases with addition of anions from Fig. 5b. To evaluate the sensitivity of 1 toward $\mathrm{Cr}_{2} \mathrm{O}_{7}{ }^{2-}$, we further examined the effect of anions concentration on fluorescence quenching. The concentration of $\mathrm{Cr}_{2} \mathrm{O}_{7}{ }^{2-}$ has been changed from 0 to $40 \mu \mathrm{M}$, at the same time, the luminescence spectra of 1 immersed in different concentrations of anion was investigated $\left(\lambda_{\mathrm{ex}}=300 \mathrm{~nm}\right)$ (Fig. 6a). The fluorescence intensity decreased with the increase of anion concentration. Subsequently, we tested the relationship between the fluorescence intensity of 1 and the reaction time. The fluorescence intensity of $\mathrm{Eu}^{3+}$ immediately decreased sharply after the addition of anions, and stabilized after $5 \mathrm{~min}$, indicating that 1 responded very quickly to anions (Fig. 6b). According to the Stern-Volmer equation [37-39]: $\mathrm{I}_{0} / \mathrm{I}=1+\mathrm{K}_{\mathrm{SV}}[\mathrm{M}]$, in which $\mathrm{I}_{0}$ and $\mathrm{I}$ means the luminescent intensity before and after the introduction of tested samples, [M]

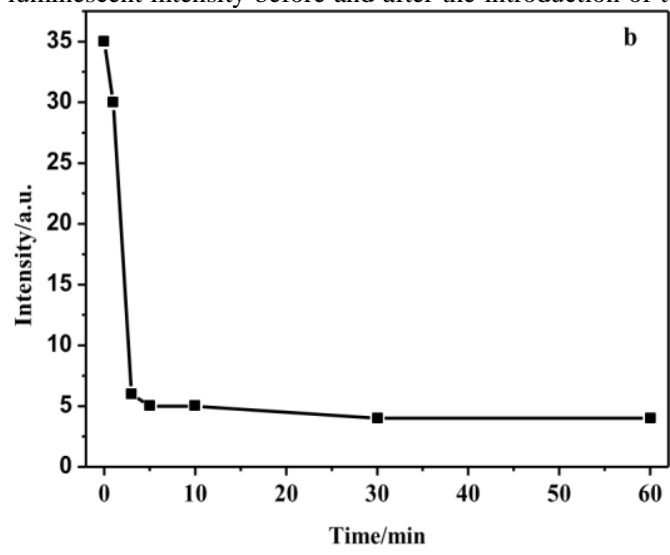

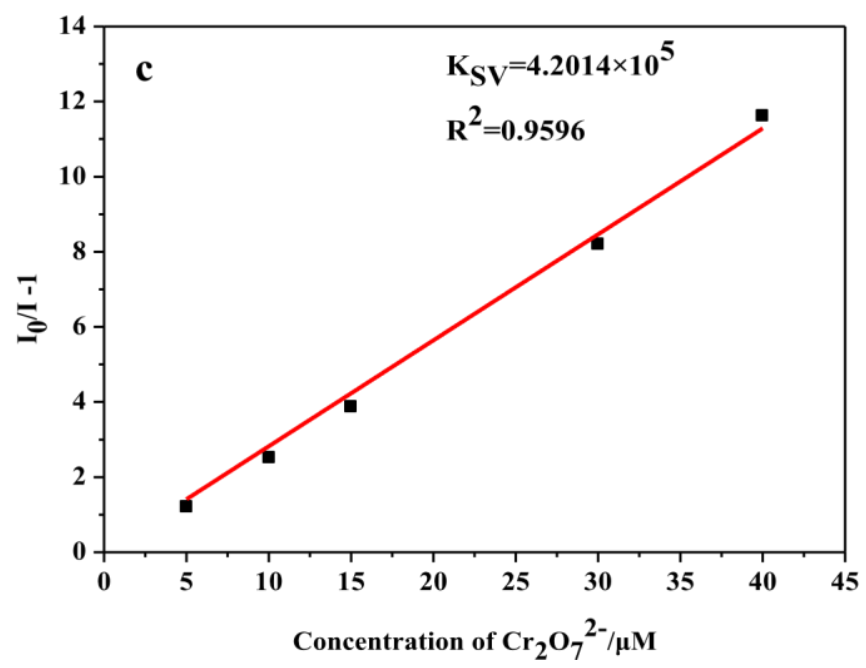

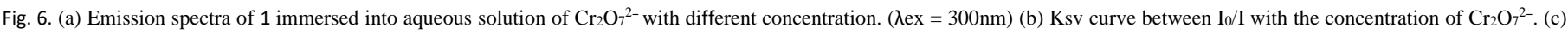
Variation of luminescent intensity of 1 at $613 \mathrm{~nm}$ with immersion time in $\mathrm{Cr}_{2} \mathrm{O}_{7}{ }^{2-}$ aqueous solution $(10 \mu \mathrm{M}) .(\lambda \mathrm{ex}=300 \mathrm{~nm})$.

aqueous solution. As shown in Fig. S9, the XRD datum of 1 immersed in aqueous solution several days and in aqueous solutions with different $\mathrm{pH}$ value $(4.0 \sim 9.0)$ are consistent with the XRD data of the original, indicating that the hybrid 1 has good structural stability. Due to the excellent luminescent properties of 1 , a series of anions are chosen to examine the sensing of 1 by immersing the small amount of as-prepared samples in the solutions $\left(10^{-3} \mathrm{~mol} / \mathrm{L}\right.$, $3 \mathrm{~mL}$ ) of different anions $\left(\mathrm{CO}_{3}{ }^{2-}, \mathrm{SO}_{4}{ }^{2-}, \mathrm{NO}_{3}{ }^{-}, \mathrm{Cl}^{-}, \mathrm{Br}^{-}, \mathrm{Cr}_{2} \mathrm{O}_{7}{ }^{2-}, \mathrm{CrO}_{4}{ }^{2-}, \mathrm{MnO}_{4}{ }^{-}\right)$ respectively. The effect of the sensing can be investigated by the luminescent represents the concentration of the tested samples, $K_{S V}$ is the coefficient of quenching. Quenching effect coefficients (Ksv) of different anions on the luminescence intensity of 1 are shown in Table S2. In this work, the corresponding $\mathrm{K}_{\mathrm{SV}}$ curve with $\mathrm{Cr}_{2} \mathrm{O}_{7}{ }^{2-}$ is showed in Fig. 6c. The calculated $\mathrm{K}_{\mathrm{SV}}$ is $4.5014 \times 10^{5}$, which demonstrates the good fluorescence quenching effect of the item. According to the standard of IUPAC $3 \sigma(\mathrm{LOD}=3 \sigma / \mathrm{k}$, $\sigma$ represents the standard deviation obtained by multiple tests on the blank, and $\mathrm{k}$ is the slope of the calibration curve), we calculated that the detection limit of the sample for 1 
is $0.68 \mu \mathrm{M}$, which shows the prepared sample has an admirable sensitivity to the detection of $\mathrm{Cr}_{2} \mathrm{O}_{7}^{2-}$. Such low LOD with the wide concentrations range of $\mathrm{Cr}_{2} \mathrm{O}_{7}{ }^{2}$ from $\mu \mathrm{M}$ to $\mathrm{mM}$ indicates the Ln-based sensor towards $\mathrm{Cr}_{2} \mathrm{O}_{7}{ }^{2-}$ sensing is reliable and feasible.

\subsection{Possible mechanism of fluorescence quenching}

We then explore the possible mechanism of fluorescence sensing of POSSPIL@ Eu. Firstly, XRD is employed to collect the structural data of the original sample and anion-contacted sample. As shown in Fig. S10, the XRD for sample immersed in $\mathrm{Cr}_{2} \mathrm{O}_{7}{ }^{2-}$ aqueous solution is similar to that of original 1, implying that basic skeletons remain unchanged in the hybrid material. In other words, the presence of $\mathrm{Cr}_{2} \mathrm{O}_{7}{ }^{2-}$ does not affect the structure of 1 . In order to further elucidate the possible sensing mechanism for the luminescence quenching by the $\mathrm{Cr}_{2} \mathrm{O}_{7}^{2-}$ ion, UV-vis spectra are used to exhibit the absorption of the ligand VIM-PA and $\mathrm{Cr}_{2} \mathrm{O}_{7}^{2-}$. As shown in Fig. S11, the absorption of VIM-PA and $\mathrm{Cr}_{2} \mathrm{O}_{7}{ }^{2-}$ can be obviously observed at the same wavelength range. From the perspective of energy transfer, it can be implied that there is a competition absorption between the ligand VIM-PA and $\mathrm{Cr}_{2} \mathrm{O}_{7}^{2-}$, the ligand is blocked from absorbing energy and then the energy transfer between VIM-PA and lanthanide ions is affected, thus generating the quenching effect of the characteristic emission of $\mathrm{Eu}^{3+}$ in the presence of $\mathrm{Cr}_{2} \mathrm{O}_{7}{ }^{2-}[40,41]$.

\section{Conclusions}

In summary, we synthesized a novel luminescent hybrid materials based on poly (ionic) liquid by copolymerization IL-PA with polyhedral oligomeric silsesquioxane (POSS), in which IL-PA was prepared by coordinating [Ln $(\mathrm{DBM})_{3}$ ] emitting precursor with IL functionalized by aryl carboxylic acid. The obtained hybrid materials showed excellent and significantly improved luminescence properties, as well as enhanced light and thermal stability. Polymer films are prepared by embedding the lanthanide hybrid materials POSS-PVIM@[Ln $\left.(\mathrm{DBM})_{3}\right]$ into polyvinylpyrrolidone and the transparent luminescent polymer films can be further used in many fields. We also obtained the white emission by adjusting the ratio of $\mathrm{Ln}^{3+}$ in the POSS-PVIM@[Ln $\left.(\mathrm{DBM})_{3}\right](\mathrm{Ln}=\mathrm{Eu}, \mathrm{Tb}, \mathrm{Gd})$. Moreover, intense white light (CIE coordinate at $(0.32,0.27))$ can be observed when the ratio of three different lanthanide cations $\left(\mathrm{Eu}^{3+}, \mathrm{Tb}^{3+}, \mathrm{Gd}^{3+}\right)$ is 1:3:3 under ultraviolet radiations with $298 \mathrm{~nm}$ laser. The quantum efficiency of the white light emission was calculated to be $38 \%$, which is superior to lots of reported whitelight-emitting materials. Due to the excellent luminescence property of POSS-PVIM@[Eu $\left.(\mathrm{DBM})_{3}\right]$, we chose it as a representative sample to explore the potential of sensing anions. Most interestingly, it can be drawn a conclusion that POSS-PVIM@ @ $\left[\mathrm{Eu}(\mathrm{DBM})_{3}\right]$ has shown promise as a new type of luminescence probe with fast response, high sensitivity and selectivity.

\section{Conflicts of interest}

There are no conflicts to declare.

\section{Acknowledgments}

This work was supported by the National Natural Science Foundation of China (21101107, 51173107), State Key Laboratory of Molecular Engineering of Polymers(Fudan University), The Staff Members of the Electron Microscopy System at the National Facility for Protein Science in Shanghai(NFPS, Zhangjiang Lab).

Appendix A. Supplementary data

Supplementary data to this article can be found online at https:// doi.org/10.1016/j.dyepig.2019.107804.
References ${ }^{1-42}$

1. Zhang, Y. F.; Xu, Z.; Zhang, F. J.; Wang, Y.; Zhao, S. L., White organic light emitting device with dyestuff DCJTB mended in polymer. Spectroscopy and Spectral Analysis 2008, 28 (4), 760-762.

2. Watanabe, K.; Sakamoto, T.; Taguchi, M.; Fujiki, M.; Nakano, T., A chiral pi-stacked vinyl polymer emitting white circularly polarized light. Chem. Commun. 2011, 47 (39), 10996-10998.

3. Wang, R.; Peng, J.; Qiu, F.; Yang, Y. L., Enhanced white-light emission from multiple fluorophores encapsulated in a single layer of diblock copolymer micelles. Chem. Commun. 2011, 47, 2787-2789

4. Prakash, A.; Katiyar, M., White polymer light emitting diode using blend of fluorescent polymers. 16th International Workshop on Physics of Semiconductor Devices 2012, 8549.

5. Park, J. J.; Park, T. J.; Jeon, W. S.; Kim, S. Y.; Lee, Y. K.; Jang, J.; Kwon, J. H., White Polymeric Light-Emitting Diodes Based on Doping of an Orange Ir Complex in a Fluorene Blue Polymer Host. Mol. Cryst. Liq. Cryst. 2009, 498, 290-297.

6. Park, J. J.; Park, T. J.; Jeon, W. S.; Kim, S. Y.; Lee, Y. K.; Jang, J.; Kwon, J. H., White polymeric light-emitting diodes based on doping of an orange Ir complex in a fluorene blue polymer. Idw '07: Proceedings of the 14th International Display Workshops, Vols 1-3 2007, 1033-1036.

7. Nicolai, H. T.; Hof, A. J.; Blom, P. W. M., Charge transport in white light-emitting polymers. Organic Optoelectronics and Photonics Ii 2006, 6192.

8. Nicolai, H. T.; Hof, A.; Blom, P. W. M., Device Physics of White Polymer Light-Emitting Diodes. Adv. Funct. Mater. 2012, 22 (10), 20402047.

9. Li, B. N.; Liu, L.; Fu, G. R.; Zhang, Z.; Li, H. Y.; Lu, X.; Wong, W. K.; Jones, R. A., Color-tunable to direct white-light and application for white polymer light emitting diode (WPLED) of organo-Eu3+- and organo-Tb3+doping polymer. J. Lumin. 2017, 192, 1089-1095.

10. Shen, F. Z.; He, F.; Lu, D.; Xie, Z. Q.; Xie, W. J.; Ma, Y. G.; Hu, B., Bright and colour stable white polymer light-emitting diodes. Semiconductor Science and Technology 2006, 21 (2), L16-L19.

11. Kim, C.; Gwon, Y. J.; Kim, J.; Lee, T. S., Synthesis of fluorescent conjugated polymer nanoparticles and their immobilization on a substrate for white light emission. Polym Chem-Uk 2018, 9 (48), 5671-5679.

12. Amin, G.; Zaman, S.; Zainelabdin, A.; Nur, O.; Willander, M., ZnO nanorods-polymer hybrid white light emitting diode grown on a disposable paper substrate. Physica Status Solidi-Rapid Research Letters 2011, 5 (2), 7173.

13. Taudt, C.; Baselt, T.; Oreski, G.; Hirschl, C.; Koch, E.; Hartmann, P., Cross-linking characterization of polymers based on their optical dispersion utilizing a white-light interferometer. Optical Measurement Systems for Industrial Inspection Ix 2015, 9525.

14. Song, H. J.; Shin, G. J.; Choi, K. H.; Lee, S.; Moon, D. K., White polymer light emitting diode materials introducing dendritic quinoxaline derivative: Synthesis, optical and electroluminescent properties. Synthetic Metals 2014, 190, 1-7.

15. Lee, H. K.; Kim, T. H.; Park, J. H.; Kim, J. K.; Park, O. O., Whitelight-emitting diodes using miscible polymer blend doped with phosphorescent dye. Organic Electronics 2011, 12 (6), 891-896.

16. Kim, J. H.; Song, W. S.; Yang, H., Color-converting bilayered composite plate of quantum-dot-polymer for high-color rendering white light-emitting diode. Opt. Lett. 2013, 38 (15), 2885-2888.

17. Kassamakov, I.; Ojala, K.; Salmia, A.; Haeggstrom, E.; Aaltonen, J.; Huber, A.; Saarikko, H.; Osterberg, M.; Oinonen, M., Characterization of dents and grooves on polymer films using scanning white light interferometry. Optical Micro- and Nanometrology in Microsystems Technology 2006, 6188.

18. Inoue, A.; Hosokawa, T.; Haishi, M.; Ohtani, N., 4-(dicyanomethylene)2-methyl-6-(p-dimethylaminostyryl)-4H-pyran (DCM)-doping density dependence of luminescence spectra and white emission in polymer lightemitting diodes. Physica Status Solidi C - Current Topics in Solid State Physics, Vol 6, No 1 2009, 6 (1), 334-337.

19. Hu, B.; Yao, C.; Huang, X. R., Designing of the White-Light Emission from a Single-Polymer System: Quantum Theoretical Study. Polymer Science Series A 2011, 53 (11), 1097-1105.

20. Fan, L. M.; Fan, W. L.; Li, B.; Zhao, X.; Zhang, X. T., W-shaped 1,3di(2,4-dicarboxyphenyl)benzene based lanthanide coordination polymers with tunable white light emission. New J. Chem. 2016, 40 (12), 10440-10446.

21. da Silva, M. A. T.; Thomazini, E. F.; Albertini, M.; Renzi, W.;

Franchello, F.; Dias, I. F. L.; Duarte, J. L.; Pocas, L. C.; Lourenco, S. A., 
Characterization of digital textile printing and polymer blend (PFODMP:P3HT) for application in manufacture of organic diodes emitting white light - WOLEDS. Optical Materials 2016, 62, 119-131.

22. Chen, M. X.; Sun, R. Y.; Ye, Y. C.; Tang, H. J.; Dong, X. Y.; Yan, J. L.; Wang, K. M.; Zhou, Q.; Wang, Z. L., Application of a novel red-emitting cationic iridium(III) coordination polymer in warm white light-emitting diodes. Optical Materials 2018, 76, 141-146.

23. Wang, R.; Peng, J.; Qiu, F.; Yang, Y. L.; Xie, Z. Y., Simultaneous blue, green, and red emission from diblock copolymer micellar films: a new approach to white-light emission. Chem. Commun. 2009, (44), 6723-6725.

24. Hrma, M.; Sichova, K.; Svoboda, J.; Vohlidal, J., Assembling of bis(tpy)fluorenes with $\mathrm{Zn} 2+$ and $\mathrm{Fe} 2+$ ions into metallo-supramolecular polymers with highly efficient white-light emission. Polymer 2017, 122, 2233.

25. Chitara, B.; Bhat, S. V.; Vivekchand, S. R. C.; Gomathi, A.; Rao, C. N. R., White-light sources based on composites of $\mathrm{GaN}$ nanocrystals with conducting polymers and nanophosphors. Solid State Communications 2008, 147 (9-10), 409-413.

26. Cheng, G.; Fei, T.; Zhao, Y.; Ma, Y. G.; Liu, S. Y., White phosphorescent polymer light-emitting devices based on a wide band-gap polymer derived from 3,6-carbazole and tetraphenylsilane. Organic Electronics 2010, 11 (3), 498-502.

27. Chen, S. A.; Chang, E. C.; Chuang, K. R.; Chao, C. I.; Wei, P. K.; Fann, W. S., Conjugated polymer blends as emitting layer for white light led. Abstr. Pap. Am. Chem. Soc. 1998, 215, U392-U392.

28. Zhen, H. Y.; Xu, W.; King, W.; Chen, Q. L.; Xu, Y. H.; Jiang, J. X.; Peng, J. B.; Cao, Y., White-light emission from a single polymer with singlet and triplet chromophores on the backbone. Macromol. Rapid Commun. 2006, 27 (24), 2095-2100.

29. Zhang, T. H.; Gong, Z. C.; Que, L., A white-light source operated polymer-based micromachined Fabry-Perot chemo/biosensor. 2009 4th Ieee International Conference on Nano/Micro Engineered and Molecular Systems, Vols 1 and 2 2009, 181-184.

30. Willander, M.; Nur, O.; Zaman, S.; Zainelabdin, A.; Bano, N.; Hussain, I., Zinc oxide nanorods/polymer hybrid heterojunctions for white light emitting diodes. J. Phys. D: Appl. Phys. 2011, 44 (22).

31. Wang, Z. W.; Gao, D. Z.; Ma, X. J.; Meng, J., White-Light

Interferometry for Measuring Fuel Pressure in Icf Polymer-Microsphere Targets. Fusion Sci. Technol. 2014, 66 (3), 432-437.

32. Wang, B. Z.; Zhang, X. P.; Liu, H. M., White-light-emitting diode based on a single-layer polymer. Aip Advances 2013, 3 (5).

33. Tian, L. L.; Zhang, W.; Yang, B.; Lu, P.; Zhang, M.; Lu, D.; Ma, Y. G.; Shen, J. C., Zinc(II)-induced color-tunable fluorescence emission in the pi-conjugated polymers composed of the bipyridine unit: A way to get whitelight emission. J. Phys. Chem. B 2005, 109 (15), 6944-6947.

34. Tang, K. C.; Tseng, S. R.; Li, W. S.; Meng, H. F.; Horng, S. F.; Hsu, C. S., Broad band and white phosphorescent polymer light-emitting diodes in multilayer structure. Synthetic Metals 2008, 158 (7), 287-291.

35. Sun, C.; Zhang, Y.; Sun, K.; Reckmeier, C.; Zhang, T. Q.; Zhang, X. Y.; Zhao, J.; Wu, C. F.; Yu, W. W.; Rogach, A. L., Combination of carbon dot and polymer dot phosphors for white light-emitting diodes. Nanoscale 2015, 7 (28), 12045-12050.

36. Roberts, R. J.; Le, D.; Leznoff, D. B., Color-Tunable and White-Light Luminescence in Lanthanide Dicyanoaurate Coordination Polymers. Inorg. Chem. 2017, 56 (14), 7948-7959.

37. Qin, L. J.; Zhu, Y. C.; Yang, H.; Ding, L.; Sun, F.; Shi, M.; Yang, S. P., White-light phosphorescence from binary coordination polymer nanoparticles. Mater. Chem. Phys. 2013, 139 (2-3), 345-349.

38. Ovens, J. S.; Christensen, P. R.; Leznoff, D. B., Designing Tunable White-Light Emission from an Aurophilic $\mathrm{Cu}-\mathrm{I} / \mathrm{Au}-\mathrm{I}$ Coordination Polymer with Thioether Ligands. Chemistry-a European Journal 2016, 22 (24), 82348239.

39. Niu, Y. H.; Liu, M. S.; Ka, J. W.; Bardeker, J.; Zin, M. T.; Schofield, R.; Chi, Y.; Jen, A. K. Y., Crosslinkable hole-transport layer on conducting polymer for high-efficiency white polymer light-emitting diodes. Adv. Mater. 2007, 19 (2), 300-+.

40. Niu, W. Y.; Sun, J. W.; Yan, P. F.; Li, Y. X.; An, G. H.; Li, G. M., 2D 1-Di-toluoyl-tartaric acid Lanthanide Coordination Polymers: Toward Singlecomponent White-Light and NIR Luminescent Materials. Chemistry-an Asian Journal 2016, 11 (4), 555-560.

41. Nam, G. H.; Park, I. K., CdSe Quantum dot-conducting polymer hybrid structure for Phosphor-free white light-emitting diodes. Journal of the Korean Physical Society 2015, 66 (5), 785-789.

42. Meng, L. C.; Lou, Z. D.; Yang, S. Y.; Hou, Y. B.; Teng, F.; Liu, X. J.; Li, Y. B., White organic light-emitting diodes based on a combined electromer and monomer emission in doubly-doped polymers. Chinese Physics B 2012, 21 (8). 